\title{
Detection and multilocus genotyping of Giardia duodenalis in dogs in Sichuan province, China
}

\author{
Yue Zhang ${ }^{1, \#}$, Zhijun Zhong, ${ }^{1, \#}$, Lei Deng ${ }^{1, \#}$, Maoqing Wang ${ }^{1, \#}$, Wei Li $^{1}$, Chao Gong ${ }^{1}$, Hualin $\mathrm{Fu}^{1}$,
} Suizhong $\mathrm{Cao}^{1}$, Xianpeng $\mathrm{Shi}^{2}$, Kongju $\mathrm{Wu}^{3}$, and Guangneng Peng ${ }^{1}$,*

${ }^{1}$ Key Laboratory of Animal Disease and Human Health of Sichuan Province, College of Veterinary Medicine, Sichuan Agricultural University, Sichuan Province 611130, P.R. China

2 Sichuan Agricultural University, Teaching Animal Hospital, Yaan, Sichuan Province 625000, P.R. China

${ }^{3}$ Chengdu Research Base of Giant Panda Breeding, Chengdu, Sichuan Province 611130, P.R. China

Received 15 May 2017, Accepted 13 July 2017, Published online 3 August 2017

\begin{abstract}
Giardia duodenalis (also known as G. intestinalis) is a flagellated protozoan that parasitizes the small intestine and is a common causal agent of zoonotic infections in humans and animals. To assess the genetic diversity and zoonotic transmission potential of $G$. duodenalis in stray dogs, 159 fecal specimens were collected from dogs in Chengdu, Yaan, and Leshan in Sichuan province, China. Of the 159 fecal samples from stray dogs, 18 (11.3\%) were G. duodenalis-positive based on nested PCR amplification of the beta giardin (bg) gene, and the occurrence varied from $1.8 \%$ to $35 \%$ in different cities. Dog-specific assemblages C $(n=9)$ and $\mathrm{D}(n=9)$ were identified. The glutamate dehydrogenase $(g d h)$ and triosephosphate isomerase $(t p i)$ genes of all $b g$-positive isolates were characterized. A total of 16 and 8 isolates were positive for the $g d h$ and $t p i$ genes, respectively. Two novel sequences of the $b g$ locus were detected among genetic assemblage $\mathrm{D}$ isolates, and one novel $g d h$ sequence and four novel tpi sequences were identified among genetic assemblage $\mathrm{C}$ isolates. Mixed infections of assemblages $\mathrm{C}$ and $\mathrm{D}$ were also detected. Assemblages A and B, which have high zoonotic potential, were not detected. Our results show that $G$. duodenalis is prevalent and a cause of diarrhea in dogs in Sichuan province, China.
\end{abstract}

Key words: Giardia, Protozoan, Dog, China, PCR.

Résumé - Détection et génotypage multilocus de Giardia duodenalis chez les chiens dans la province du Sichuan, en Chine. Giardia duodenalis (également connu sous le nom de G. intestinalis), est un protozoaire flagellé qui parasite l'intestin grêle et un agent causal commun d'infections zoonotiques chez les humains et les animaux. Pour évaluer la diversité génétique et le potentiel de transmission zoonotique de $G$. duodenalis chez les chiens errants, 159 échantillons de matières fécales ont été prélevés chez des chiens à Chengdu, Yaan et Leshan, dans la province du Sichuan, en Chine. Sur 159 échantillons de matières fécales provenant de chiens errants, $18(11.3 \%)$ étaient positifs pour $G$. duodenalis sur la base de l'amplification par PCR imbriquée du gène de la bêta giardine $(b g)$, et l'occurrence variait de $1.8 \%$ à $35 \%$ dans différentes villes. Les assemblages spécifiques au chien $\mathrm{C}(n=9)$ et $\mathrm{D}(n=9)$ ont été identifiés. Le gène de la glutamate déshydrogénase $(g d h)$ et le triosephosphate isomérase (tpi) de tous les isolats bg-positifs ont été caractérisés. Au total, 16 et 8 isolats étaient positifs pour les gènes $g d h$ et $t p i$, respectivement. Deux nouvelles séquences du locus $b g$ ont été détectées parmi les isolats d'assemblage génétique $\mathrm{D}$, et une nouvelle séquence $g d h$ et quatre nouvelles séquences tpi ont été identifiées parmi les isolats d'assemblage génétique $\mathrm{C}$. Des infections mixtes des assemblages $\mathrm{C}$ et $\mathrm{D}$ ont également été détectées. Les assemblages A et $\mathrm{B}$, qui ont un potentiel zoonotique élevé, n’ont pas été détectés. Nos résultats montrent que G. duodenalis est répandu et une cause de diarrhées chez les chiens dans la province du Sichuan, en Chine.

\section{Introduction}

Giardia duodenalis, also known as $G$. intestinalis or G. lamblia, is an important zoonotic intestinal parasite that infects humans and a variety of domestic and wild animals [18]. G. duodenalis has high potential for zoonotic transmission via water or feces; diarrhea is a major clinical sign of infection. In humans, G. duodenalis can infect immunocompromised

\footnotetext{
\# These authors contributed equally to this work.

*Corresponding author: m18283579140@163.com
}

This is an Open Access article distributed under the terms of the Creative Commons Attribution License (http://creativecommons.org/licenses/by/4.0), which permits unrestricted use, distribution, and reproduction in any medium, provided the original work is properly cited. 
hosts [21], such as AIDS patients, and can be life-threatening. G. duodenalis has been reported in livestock $[12,16,26]$, wildlife [13, 20], and companion animals [10, 11, 15, 27]; it infects numerous mammalian species, including humans and species that are closely connected with humans. It is distributed worldwide and poses a threat to public health.

There are eight known genotypes $(\mathrm{A}-\mathrm{H})$ of $\mathrm{G}$. duodenalis [7]. Assemblages A and B have zoonotic potential and can infect humans [5], cattle [28], sheep [26], dogs [19], and cats [2]. Specifically, subgenotypes of assemblages A (subtypes A1, A2, A3, and A4) and B (subtypes B1 and B4) are associated with human infections [5]. Hence, assemblages $\mathrm{A}$ and $\mathrm{B}$ are considered zoonotic genotypes. Genetic assemblages $\mathrm{C}-\mathrm{H}$ have been reported in specific hosts. Assemblages $\mathrm{C}$ and $\mathrm{D}$ are observed in canines [10,11,27]. Assemblage $\mathrm{E}$ has been reported in cattle [12]. Assemblage $\mathrm{F}$ is specific to cats, pigs, and cetaceans $[1,15,20]$, and assemblage $G$ is specific to mice and rats [30]. Assemblage $\mathrm{H}$ was reported in the grey seal and gulls [9].

Many recent epidemiological studies have reported G. duodenalis infections in dogs in China [10, 11, 19, 27], Japan [8], and Brazil [4]. In Heilongjiang and Shanghai, China [11, 27], zoonotic genetic assemblages A and B have been observed in pet dogs. Stray dogs, considered important vehicles, have played a significant role in transmission to humans in developing countries. However, little is known about the prevalence of G. duodenalis in stray dogs in China. In developing countries, stray dogs are common and have a wide distribution. In this study, nested PCR was used to amplify the beta giardin $(b g)$, glutamate dehydrogenase $(g d h)$, and triosephosphate isomerase (tpi) loci to investigate the prevalence and genotypes of G. duodenalis in stray dogs in Sichuan province, China.

\section{Materials and methods}

\section{Fecal specimen collection}

From November 2016 to January 2017, 159 fecal specimens were collected from stray dogs in shelters in Chengdu, Yaan, and Leshan cities in Sichuan province, China. Forty specimens whose hosts had diarrhea were obtained from Chengdu. Sixty-three and 56 specimens whose hosts did not exhibit diarrhea were obtained from Yaan and Leshan, respectively. All dogs were stray and abandoned and were housed in shelters for at least 2 months. Fecal samples were collected, numbered in plastic containers, and transported to our laboratory in ice packs on the day of collection. These fecal specimens were stored in a $4{ }^{\circ} \mathrm{C}$ refrigerator.

\section{DNA extraction}

Fecal specimens $(50-100 \mathrm{mg})$ were removed from each plastic container. DNA was extracted directly from fecal samples using an E.Z.N.A. Stool DNA Kit (Omega Biotek, Norcross, GA, USA), according to the protocol recommended by the manufacturer. DNA samples were stored at $-20{ }^{\circ} \mathrm{C}$ until use for PCR.

\section{PCR amplification}

G. duodenalis was detected by nested PCR amplification of an approximately 530-bp fragment of the $b g$ locus. The $b g$-positive products were further characterized by amplification of $g d h$ and $t p i$. The primers for PCR amplification and annealing temperatures for the three genes were obtained from Zhang et al. [29]. Each reaction included $12.5 \mu \mathrm{L}$ of $2 \times \mathrm{Taq}$ PCR Master Mix (KT201-02; Tiangen, Beijing, China), $8.5 \mu \mathrm{L}$ of deionized water (Tiangen), $2 \mu \mathrm{L}$ of DNA, and $1 \mu \mathrm{L}$ each of upstream and downstream primers, for a total volume of $25 \mu \mathrm{L}$. Positive and negative controls were included in each test. All secondary amplifications were visualized under UV light after electrophoresis on a $1 \%$ agarose gel mixed with Golden View.

\section{Nucleotide sequencing and analysis}

All positive secondary PCR products were sent to Sangon Biotech Company (Shanghai, China) for sequencing. Genotypes with mutations, including single nucleotide substitutions, deletions, or insertions, were confirmed by DNA sequencing of at least two PCR products. Assemblages and subtypes were identified by the alignment of the nucleotide sequences with known reference sequences for $b g$, tpi, and gdh of $G$. duodenalis available in the GenBank database using BLAST and Clustal X.

\section{Phylogenetic analysis}

To assess the genetic relationships among $G$. duodenalis genotypes and previously published reference sequences in GenBank, a phylogenetic analysis was performed. A neighbor-joining tree was constructed using Mega 6 based on evolutionary distances calculated with the Kimura 2-parameter model. The reliability of trees was assessed using a bootstrap analysis with 1,000 replicates.

\section{Statistical analysis}

The $\chi^{2}$ test was used to compare the infection rates of G. duodenalis at three stray dog shelters in different cities, and differences were considered significant when $p<0.05$.

\section{Results}

\section{Occurrence of G. duodenalis}

In this study, 18 (11.3\%) positive specimens were obtained from 159 fecal specimens by nested PCR amplification of the bg locus. Among positive specimens, 14 were obtained from dogs with diarrhea and 4 from dogs without diarrhea. The occurrence rates in dogs with and without diarrhea were $35.0 \%$ and $3.4 \%$, respectively. The infection rates of dogs with diarrhea were highly significantly different from dogs without diarrhea. $\left(\chi^{2}=29.85, p<0.01\right)$. Multilocus sequence typing at $b g, g d h$, and tpi revealed the presence of G. duodenalis 
Table 1. Prevalence and distribution of Giardia duodenalis by location in Sichuan province, China.

\begin{tabular}{lccc}
\hline Location (city) & No. samples & No. positive (\%) & Genotype $(n)$ \\
\hline Chengdu & 40 & $14(35.0 \%)$ & Assemblage C (8); assemblage D (6) \\
Yaan & 63 & $3(4.8 \%)$ & Assemblage C (1); assemblage D (2) \\
Leshan & 56 & $1(1.8 \%)$ & Assemblage D (1) \\
Total & 159 & $18(11.3 \%)$ & Assemblage C (9); assemblage D (9); assemblage C/D (4) \\
\hline
\end{tabular}

(A)

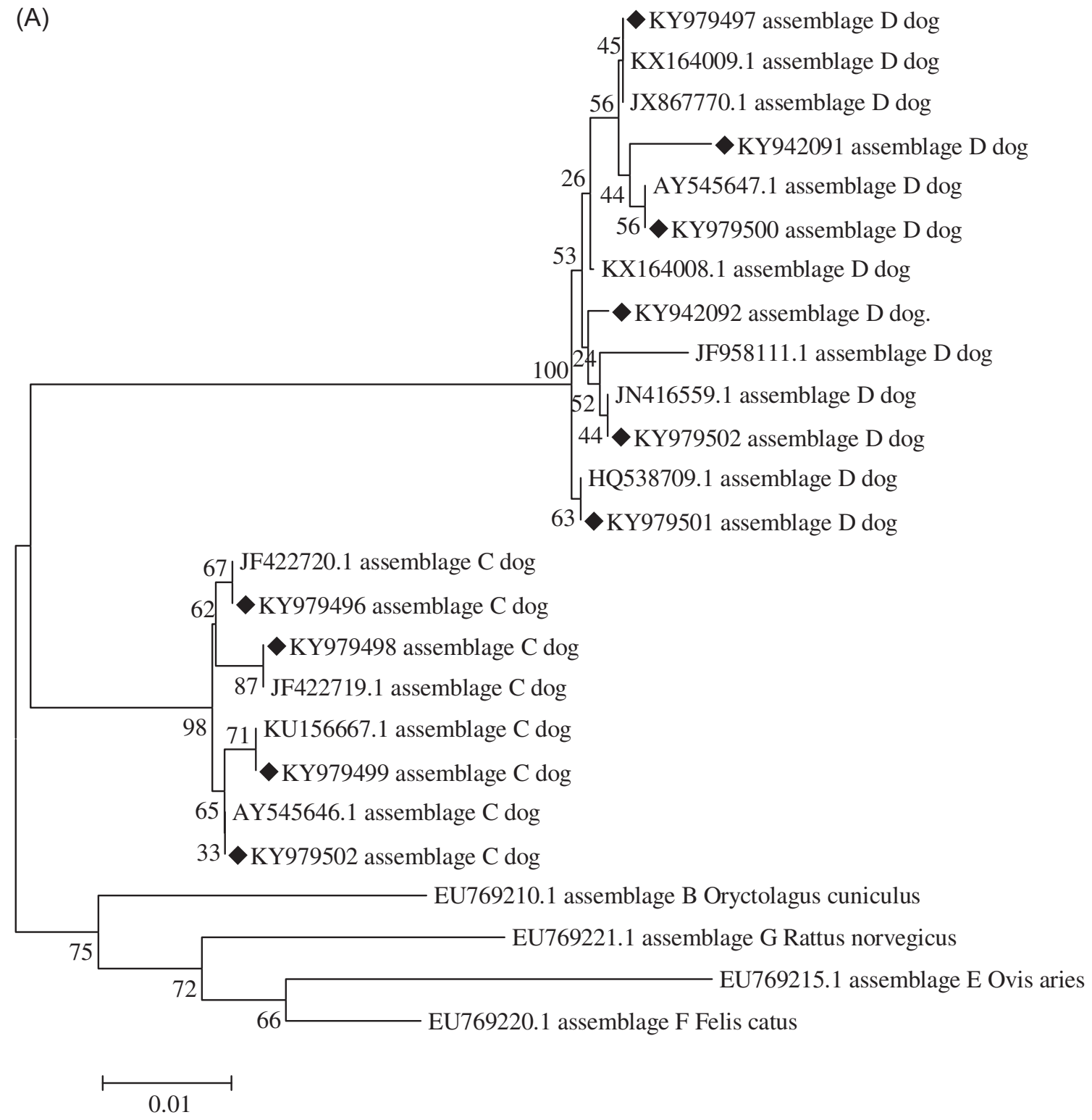

Figure 1. Phylogenetic relationships of Giardia duodenalis at the $b g$, gdh, and tpi loci. The relationships between G. duodenalis genotypes identified in this study and other known genotypes deposited in GenBank were inferred by a neighbor-joining analysis of three genetic loci using the Kimura 2-parameter model. Bootstrap values greater than 50\% from 1,000 replicates are shown. (A) Tree based on the beta giardin (bg) gene. (B) Tree based on the glutamate dehydrogenase $(g d h)$ gene. (C) Tree based on the triosephosphate isomerase (tpi) gene. Sequences obtained in this study are marked with " $\diamond$ ".

assemblages C (13) and D (9). The infection rate in Chengdu was highest $(35 \% ; 14 / 40)$, followed by Yaan $(4.8 \% ; 3 / 63)$ and Leshan $(1.8 \% ; 1 / 56)$ based on amplification of the $b g$ locus.
The genotypes of all positive specimens are listed in Table 1. Additionally, we found mixed infections in four samples, CD18, CD32, YA16, and YA60. 
(B)
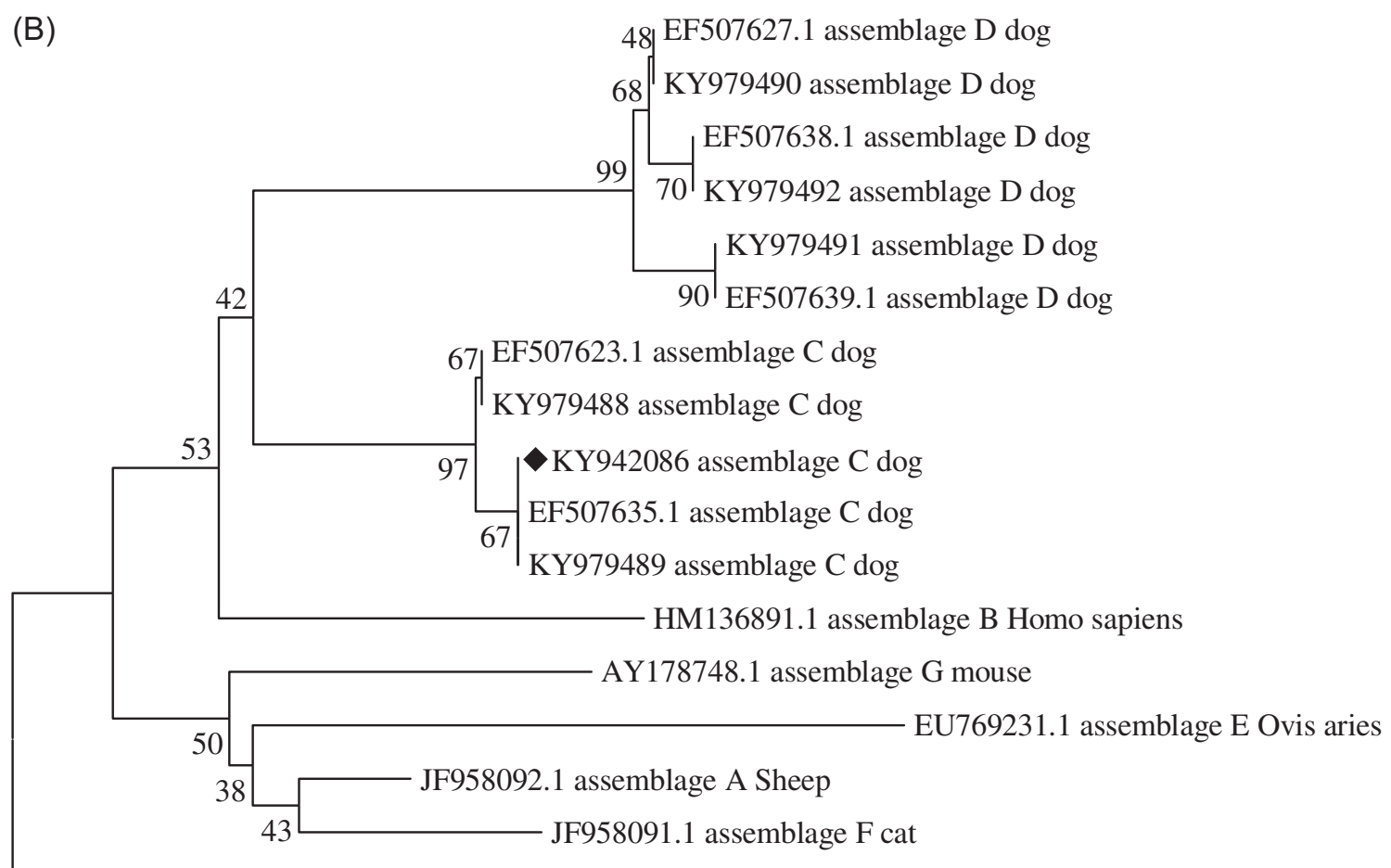

GU176098.1 assemblage $\mathrm{H}$

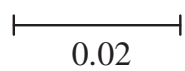

Figure 1. Continued.

\section{Molecular analysis}

A total of 18 positive specimens were identified by nested PCR, and a phylogenetic analysis based on $b g, g d h$, and $t p i$ is summarized in Figure 1. All positive specimens at different loci are listed in Table 2. A multilocus sequencing analysis further identified subtypes of assemblages C and D (see Table 3 for accession numbers).

\section{Summary of $b g$ results}

All isolates obtained from dogs were assemblages C and D, including nine that were assemblage $\mathrm{C}$ and nine that were assemblage D (Fig. 1A). Among these isolates, two had single nucleotide polymorphisms (SNPs) compared with the reference sequences downloaded from GenBank. For assemblage D, CD23 was similar to KX164009 with two SNPs (substitution: $\mathrm{A} / \mathrm{C}$ and $\mathrm{C} / \mathrm{A}$ ), and YA16 was similar to KF958111 with one SNP (substitution: C/A).

\section{Summary of $g d h$ results}

Among 16 isolates from dogs, 12 were identified as assemblage C and 4 as assemblage D (Fig. 1B). The YA16 isolate had a SNP compared with the reference sequences downloaded from GenBank. At the $g d h$ locus, YA16 was similar to EF507635 with two SNPs (substitution: A/G and T/C).

\section{Summary of tpi results}

Eight isolates were identified as assemblage $\mathrm{C}$ at the tpi locus (Fig. 1C). Among eight isolates, five had a SNP and two isolates, CD21 and YA49, had the same SNP compared with the reference sequence downloaded from GenBank. For the tpi locus, an alignment of all eight assemblage $\mathrm{C}$ sequences was generated. CD40 was similar to EU781005 with a SNP (substitution: A/G). CD18 was similar to KX014801 with two SNPs (substitution: G/A and G/A). CD21 and YA49 were similar to KX014804 with a SNP (substitution: A/G). CD28 was similar to KF993723 with a SNP (substitution: A/C).

\section{Discussion}

In China, the prevalence of $G$. duodenalis in dogs has been reported in Heilongjiang [11], Shanghai [27], Guangdong [10], and Henan [19]. Four genotypes, assemblages A, B, C, and D, have been identified in Shanghai in pet dogs [27]. For stray dogs, only assemblages $C$ and $D$ have been identified in Henan [19]. Assemblage E, infecting cattle, has been identified in dogs in Heilongjiang province [11]. In total, five genotypes, i.e., assemblages A, B, C, D, and E, have been found in dogs in China. The prevalent assemblages differ among different areas in China. Five genotypes have been found in Canada. The prevalent genotypes of $G$. duodenalis in dogs in Japan 
(C)

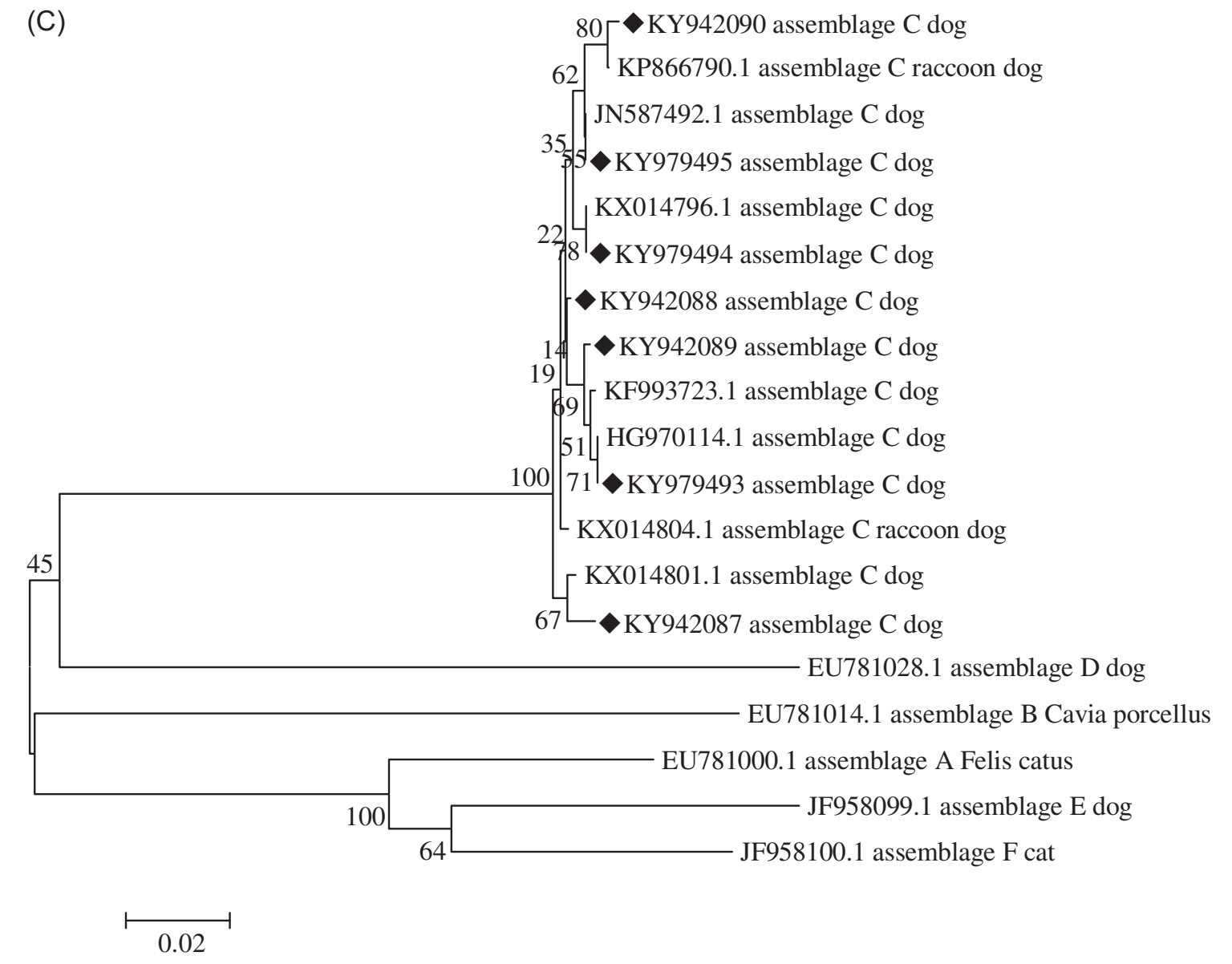

Figure 1. Continued.

[8], Brazil [4], Poland [17], the Netherlands [14], and England [23] are shown in Table 4.

In most studies of $G$. duodenalis in dogs, assemblages $\mathrm{C}$ and $\mathrm{D}$, host-specific genotypes, are considered dominant $[10$, $19,27]$. Other assemblages, such as assemblage E reported in Heilongjiang [11], have zoonotic potential, to a certain extent. In this study, only the host-specific assemblages $\mathrm{C}$ and $\mathrm{D}$ were found in stray dogs, similar to previous results in Henan [19]. Moreover, a high frequency of mixed infections of $G$. duodenalis has been reported in previous multilocus analyses [19, 27]. A multilocus genotype method (tpi, gdh, and $b g$ loci) is widely used for the detection of $G$. duodenalis co-infection in humans and animals $[3,19,26,27]$. In this study, mixed infections of assemblages $\mathrm{C}$ and $\mathrm{D}$ were also observed, which is consistent with other studies in dogs [19, 27]. Owing to the low levels of contact between people and stray dogs in China, the zoonotic assemblages A and B were not found in this study, which is consistent with another study in Henan [19]. However, the identification of genotype $\mathrm{A} 1$ in both a child and his dog in Brazil [24] suggests that the infection in the dog resulted from contact with G. duodenalis-infected feces of the owner.

Multilocus sequence typing was used for the genetic characterization of $G$. duodenalis in this study. The $b g, g d h$, and $t p i$ loci varied with respect to PCR amplification rates, consistent
Table 2. Genotypes of Giardia duodenalis isolates from dogs in Chengdu, Yaan, and Leshan in Sichuan province, China at the $b g$, gdh, and tpi loci.

\begin{tabular}{lccc}
\hline Isolates & $b g$ & $g d h$ & $t p i$ \\
\hline CD02 & C & Neg & Neg \\
CD17 & C & C & C \\
CD18 & D & C & C \\
CD21 & C & C & C \\
CD23 & C & Neg & Neg \\
CD25 & C & C & C \\
CD27 & D & D & Neg \\
CD28 & C & C & C \\
CD31 & C & C & Neg \\
CD32 & D & C & Neg \\
CD33 & D & D & Neg \\
CD35 & D & D & Neg \\
CD36 & D & D & Neg \\
CD40 & C & C & C \\
YA16 & D & C & Neg \\
YA49 & C & C & C \\
YA60 & D & C & C \\
LS19 & D & D & Neg \\
\hline
\end{tabular}

Note: CD represents Chengdu, YA represents Yaan, and LS represents Leshan; Neg represents negative. 
Table 3. Sequences with SNPs and corresponding accession numbers.

\begin{tabular}{lcccc}
\hline Isolate code & Gene & Genotype & Accession number (new sequence) & Compared accession number \\
\hline CD23 & $b g$ & Assemblage D & KY942091 & KX164009 \\
YA16 & $b g$ & Assemblage D & KY942092 & KX164008 \\
CD02/17/21 & $b g$ & Assemblage C & KY979496 & JF422720 \\
CD18/27 & $b g$ & Assemblage D & KY979497 & JX867770 \\
CD25/28/36/40 & $b g$ & Assemblage C & KY979498 & JF422719 \\
CD31 & $b g$ & Assemblage C & KY9795950 & KU156667 \\
CD23/35 & $b g$ & Assemblage D & KY979501 & KX164009 \\
CD33/YA60 & $b g$ & Assemblage D & KY979502 & HQ538709 \\
YA49/ & $b g$ & Assemblage C & KY979503 & AY545646 \\
LS19 & $b g$ & Assemblage D & KY942086 & JN416559 \\
YA16 & $g d h$ & Assemblage C & KY97948489 & EF507635 \\
CD17/Y49 & $g d h$ & Assemblage C & KY979490 & EF507623 \\
CD18/21/25/28/31/32/40/YA60 & $g d h$ & Assemblage C & KY979491 & EF507635 \\
CD27/33 & $g d h$ & Assemblage D & KY979492 & EF507627 \\
CD35 & $g d h$ & Assemblage D & KY942087 & EF507639 \\
LA19 & $g d h$ & Assemblage D & KY942088 & EF507638 \\
CD18 & $t p i$ & Assemblage C & KY942089 & KX014801 \\
CD21/YA49 & $t p i$ & Assemblage C & KY942090 & KX014804 \\
CD28 & $t p i$ & Assemblage C & KY9794933 & KF993723 \\
CD40 & $t p i$ & Assemblage C & KY979494 & KP866790 \\
CD17 & $t p i$ & Assemblage C & KY979495 & HG970114 \\
CD25 & $t p i$ & Assemblage C & & KX014796 \\
YA60 & $t p i$ & Assemblage C & JN587492 \\
\hline
\end{tabular}

Table 4. Prevalence of Giardia duodenalis in different sample sources in China and other countries by amplification of the $b g$ locus.

\begin{tabular}{llcc}
\hline Country/Province & Feces source & Genotypes & Reference \\
\hline China & & & \\
Shanghai & Pet dogs & A, B, C, D & {$[27]$} \\
Guangdong & Pet dogs & A, D & {$[10]$} \\
Heilongjiang & Stray dogs & & {$[11]$} \\
& Pet dogs & C, E & {$[11]$} \\
Henan & Stray dogs & C, D & {$[19]$} \\
& Pet dogs & C, D & \\
Sichuan & Stray dogs & C, D & \\
Total & Stray dogs & C, D & \\
& Pet dogs & A, B, C, D & \\
Other country & \multicolumn{4}{c}{} \\
Japan & Pet dogs & C, D & {$[8]$} \\
Brazil & Pet dogs & A, B, C, D & {$[4]$} \\
Poland & Pet dogs & B, C, D & {$[17]$} \\
Spain & Stray dogs & A, B, C, D & {$[6]$} \\
Canada & Stray dogs & C, D, E & {$[22]$} \\
& Pet dogs & A, B, C, D, E & {$[22]$} \\
The Netherlands & Pet dogs & A, C, D & {$[14]$} \\
England & Stray dogs & C, D \\
Total & Stray dogs & A, B, C, D, E & {$[23]$} \\
& Pet dogs & A, B, C, D, E & \\
\hline
\end{tabular}

with most previous multilocus typing studies of $G$. duodenalis $[2,19,25]$. The stray dogs in our study did not harbor zoonotic genotypes of $G$. duodenalis, indicating a minimal role in zoonotic transmission in Sichuan province, China.

The results obtained in this study demonstrate that genetic assemblages $\mathrm{C}$ and $\mathrm{D}$ of $G$. duodenalis are present in stray dogs in Sichuan province, China. Zoonotic genotypes (assemblages A and B) were not found, suggesting that these genotypes are not prevalent in stray dogs in Sichuan province, China. Moreover, new subtypes were identified. Nevertheless, G. duodenalis is a prevalent protozoan parasite, and although zoonotic assemblages were not found in stray dogs in this study, potential transmission should not be overlooked. Certain measures should be taken to reduce the possibility of intraspecific transmission.

\section{Conflict of interest}

The authors declare that they have no conflict of interest.

Acknowledgements. The study was supported financially by the National Science and Technology Department "13th five-year" Special Subproject of China (No. 2016YFD0501009) and the Chengdu Giant Panda Breeding Research Foundation (CPF2014-10).

\section{References}

1. Armson A, Yang R, Thompson J, Johnson J, Reid S, Ryan UM. 2009. Giardia genotypes in pigs in Western Australia: prevalence and association with diarrhea. Experimental Parasitology, 121(4), 381-383.

2. Ballweber LR, Xiao L, Bowman DD, Kahn G, Cama VA. 2010. Giardiasis in dogs and cats: update on epidemiology and public health significance. Trends in Parasitology, 26(4), 180-189.

3. Caccio SM, Beck R, Lalle M, Marinculic A, Pozio E. 2008. Multilocus genotyping of Giardia duodenalis reveals striking differences between assemblages $\mathrm{A}$ and $\mathrm{B}$. International Journal for Parasitology, 38(13), 1523-1531. 
4. Fava NM, Soares RM, Scalia LA, Cunha MJ, Faria ES, Cury MC. 2016. Molecular typing of canine Giardia duodenalis isolates from Minas Gerais, Brazil. Experimental Parasitology, $161,1-5$

5. Feng Y, Xiao L. 2011. Zoonotic potential and molecular epidemiology of Giardia species and giardiasis. Clinical Microbiology Reviews, 24(1), 110-140.

6. Gil H, Cano L, de Lucio A, Bailo B, de Mingo MH, Cardona GA, Fernandez-Basterra JA, Aramburu-Aguirre J, LopezMolina N, Carmena D. 2017. Detection and molecular diversity of Giardia duodenalis and Cryptosporidium spp. in sheltered dogs and cats in Northern Spain. Infection, Genetics and Evolution, 50, 62-69.

7. Heyworth MF. 2016. Giardia duodenalis genetic assemblages and hosts. Parasite, 23, 13.

8. Itoh N, Itagaki T, Kawabata T, Konaka T, Muraoka N, Saeki H, Kanai K, Chikazawa S, Hori Y, Hoshi F, Higuchi S. 2011. Prevalence of intestinal parasites and genotyping of Giardia intestinalis in pet shop puppies in east Japan. Veterinary Parasitology, 176(1), 74-78.

9. Lasek-Nesselquist E, Welch DM, Sogin ML. 2010. The identification of a new Giardia duodenalis assemblage in marine vertebrates and a preliminary analysis of $G$. duodenalis population biology in marine systems. International Journal for Parasitology, 40(9), 1063-1074.

10. Li J, Zhang P, Wang P, Alsarakibi M, Zhu H, Liu Y, Meng X, Li J, Guo J, Li G. 2012. Genotype identification and prevalence of Giardia duodenalis in pet dogs of Guangzhou, Southern China. Veterinary Parasitology, 188(3-4), 368-371.

11. Li W, Li Y, Song M, Lu Y, Yang J, Tao W, Jiang Y, Wan Q, Zhang S, Xiao L. 2015. Prevalence and genetic characteristics of Cryptosporidium, Enterocytozoon bieneusi and Giardia duodenalis in cats and dogs in Heilongjiang province, China. Veterinary Parasitology, 208(3-4), 125-134.

12. Liu G, Su Y, Zhou M, Zhao J, Zhang T, Ahmad W, Lu H, Jiang N, Chen Q, Xiang M, Yin J. 2015. Prevalence and molecular characterization of Giardia duodenalis isolates from dairy cattle in northeast China. Experimental Parasitology, 154, 20-24.

13. Mateo M, de Mingo MH, de Lucio A, Morales L, Balseiro A, Espi A, Barral M, Lima Barbero JF, Habela MA, FernandezGarcia JL, Bernal RC, Koster PC, Cardona GA, Carmena D. 2017. Occurrence and molecular genotyping of Giardia duodenalis and Cryptosporidium spp. in wild mesocarnivores in Spain. Veterinary Parasitology, 235, 86-93.

14. Overgaauw PA, van Zutphen L, Hoek D, Yaya FO, Roelfsema J, Pinelli E, van Knapen F, Kortbeek LM. 2009. Zoonotic parasites in fecal samples and fur from dogs and cats in The Netherlands. Veterinary Parasitology, 163(1-2), 115-122.

15. Paoletti B, Otranto D, Weigl S, Giangaspero A, Di Cesare A, Traversa D. 2011. Prevalence and genetic characterization of Giardia and Cryptosporidium in cats from Italy. Research in Veterinary Science, 91(3), 397-399.

16. Peng XQ, Tian GR, Ren GJ, Yu ZQ, Lok JB, Zhang LX, Wang XT, Song JK, Zhao GH. 2016. Infection rate of Giardia duodenalis, Cryptosporidium spp. and Enterocytozoon bieneusi in cashmere, dairy and meat goats in China. Infection, Genetics and Evolution, 41, 26-31.

17. Piekarska J, Bajzert J, Gorczykowski M, Kantyka M, Podkowik M. 2016. Molecular identification of Giardia duodenalis isolates from domestic dogs and cats in Wroclaw, Poland. Annals of Agricultural and Environmental Medicine, 23(3), 410-415.

18. Plutzer J, Ongerth J, Karanis P. 2010. Giardia taxonomy, phylogeny and epidemiology: Facts and open questions. International Journal of Hygiene and Environmental Health, 213(5), 321-333.

19. Qi M, Dong H, Wang R, Li J, Zhao J, Zhang L, Luo J. 2016. Infection rate and genetic diversity of Giardia duodenalis in pet and stray dogs in Henan Province. China. Parasitology International, 65(2), 159-162.

20. Reboredo-Fernandez A, Ares-Mazas E, Martinez-Cedeira JA, Romero-Suances R, Cacció SM, Gomez-Couso H. 2015. Giardia and Cryptosporidium in cetaceans on the European Atlantic coast. Parasitology Research, 114(2), 693-698.

21. Thompson RC. 2004. The zoonotic significance and molecular epidemiology of Giardia and giardiasis. Veterinary Parasitology, 126(1-2), 15-35.

22. Uehlinger FD, Greenwood SJ, McClure JT, Conboy G, O'Handley R, Barkema HW. 2013. Zoonotic potential of Giardia duodenalis and Cryptosporidium spp. and prevalence of intestinal parasites in young dogs from different populations on Prince Edward Island, Canada. Veterinary Parasitology, 196(3-4), 509-514.

23. Upjohn M, Cobb C, Monger J, Geurden T, Claerebout E, Fox M. 2010. Prevalence, molecular typing and risk factor analysis for Giardia duodenalis infections in dogs in a central London rescue shelter. Veterinary Parasitology, 172(3-4), 341-346.

24. Volotao AC, Costa-Macedo LM, Haddad FS, Brandao A, Peralta JM, Fernandes O. 2007. Genotyping of Giardia duodenalis from human and animal samples from Brazil using beta-giardin gene: a phylogenetic analysis. Acta Tropica, 102(1), 10-19.

25. Wang A, Ruch-Gallie R, Scorza V, Lin P, Lappin MR. 2012. Prevalence of Giardia and Cryptosporidium species in dog park attending dogs compared to non-dog park attending dogs in one region of Colorado. Veterinary Parasitology, 184(2-4), 335-340.

26. Wang H, Qi M, Zhang K, Li J, Huang J, Ning C, Zhang L. 2016. Prevalence and genotyping of Giardia duodenalis isolated from sheep in Henan Province, central China. Infection, Genetics and Evolution, 39, 330-335.

27. Xu H, Jin Y, Wu W, Li P, Wang L, Li N, Feng Y, Xiao L. 2016. Genotypes of Cryptosporidium spp., Enterocytozoon bieneusi and Giardia duodenalis in dogs and cats in Shanghai, China. Parasites \& Vectors, 9, 121.

28. Zhang XX, Tan QD, Zhao GH, Ma JG, Zheng WB, Ni XT, Zhao Q, Zhou DH, Zhu XQ. 2016. Prevalence, risk factors and multilocus genotyping of Giardia intestinalis in dairy cattle, Northwest China. Journal of Eukaryotic Microbiology, 63(4), 498-504.

29. Zhang XX, Zheng WB, Ma JG, Yao QX, Zou Y, Bubu CJ, Zhao Q, Zhu XQ. 2016. Occurrence and multilocus genotyping of Giardia intestinalis assemblage $\mathrm{C}$ and $\mathrm{D}$ in farmed raccoon dogs, Nyctereutes procyonoides, in China. Parasites \& Vectors, 9, 471 .

30. Zhao Z, Wang R, Zhao W, Qi M, Zhao J, Zhang L, Li J, Liu A. 2015. Genotyping and subtyping of Giardia and Cryptosporidium isolates from commensal rodents in China. Parasitology, 142(6), 800-806. 
Cite this article as: Zhang Y, Zhong Z, Deng L, Wang M, Li W, Gong C, Fu H, Cao S, Shi X, Wu K \& Peng G: Detection and multilocus genotyping of Giardia duodenalis in dogs in Sichuan province, China. Parasite, 2017, 24, 31.

\section{O PARASTE}

An international open-access, peer-reviewed, online journal publishing high quality papers on all aspects of human and animal parasitology

Reviews, articles and short notes may be submitted. Fields include, but are not limited to: general, medical and veterinary parasitology; morphology, including ultrastructure; parasite systematics, including entomology, acarology, helminthology and protistology, and molecular analyses; molecular biology and biochemistry; immunology of parasitic diseases; host-parasite relationships; ecology and life history of parasites; epidemiology; therapeutics; new diagnostic tools.

All papers in Parasite are published in English. Manuscripts should have a broad interest and must not have been published or submitted elsewhere. No limit is imposed on the length of manuscripts.

Parasite (open-access) continues Parasite (print and online editions, 1994-2012) and Annales de Parasitologie Humaine et Comparée (1923-1993) and is the official journal of the Société Française de Parasitologie. 